\title{
Estereótipos de género e sexismo em docentes do ensino superior
}

\author{
Catarina Sales-Oliveira, Susana Villas-Boas e Soledad Las-Heras
}

\begin{abstract}
RESUMO
A socialização de género ocorre quotidianamente e marca de forma indelével a identidade individual bem como a cultura das organizações e grupos. A interação entre discentes e docentes faz parte do processo de socialização de género, assim diversas investigações mostram que a atenção dada e as expectativas de docentes em relação a alunos e alunas são diferenciadas. Esta investigação procurou analisar e caracterizar um grupo de docentes universitários portugueses, mulheres e homens, as quanto aos seus estereótipos de género e sexismo, de modo a promover a reflexão do conjunto de agentes educativos envolvidos. Os resultados obtidos permitem-nos concluir que estes e estas docentes possuem estereótipos de género, mas com algumas particularidades interessantes, como o facto de às mulheres serem atribuídas maior carga de traços instrumentais. Verificou-se igualmente qual e o tipo de sexismo que predomina é o sexismo ambivalente, sendo que os homens apresentam atitudes sexistas significativamente mais hostis do que as mulheres.
\end{abstract}

Palavras chave: estereótipos de género, sexismo, socialização de género, ensino superior.

Catarina Sales-Oliveira

catarinasalesoliveira@gmail.com Portuguesa. Doutorada em Sociologia pelo ISCTE _ IUL. Professora Auxiliar na UBI e Investigadora do CIESIUL. Áreas de investigação: género; trabalho e organizações; mobilidade e transportes.

Susana Villas-Boas

suvboas@gmail.com Portuguesa. Mestre em Ciências da Educação pela Universidade de Coimbra. Doutoranda da FPCE-UC com Bolsa da Fundação para a Ciência e Tecnologia e Investigadora do CEMRI-UA. Áreas de investigação: género, educação intercultural e educação intergeracional.

Soledad Las-Heras

slhperez@gmail.com

Espanhola. Mestre em Sociologia pela Universidade Complutense de Madrid. Áreas de investigação: género, mercado de trabalho, desigualdade e estratificação social. 


\title{
Estereotipos de género y sexismo en docentes de educación superior
}

\section{RESUMEN}

La socialización de género ocurre cotidianamente y marca de forma indeleble la identidad individual, así como la cultura de las organizaciones y de los grupos. La interacción entre discentes e docentes forma parte del proceso de socialización de género. De ese modo, diversas investigaciones muestran que la atención que se presta y las expectativas que los docentes tienen de los alumnos y las alumnas son diferentes. En esta investigación se buscó analizar y caracterizar a un grupo de docentes universitarios portugueses, mujeres y hombres, en cuanto a sus estereotipos de género y sexismo, con el objetivo de promover la reflexión del conjunto de agentes educativos involucrados. Los resultados obtenidos nos permiten concluir que esos y esas docentes poseen estereotipos de género, pero con algunas particularidades interesantes, como el hecho de que a las mujeres se les atribuye mayor carga de rasgos instrumentales. Igualmente, se verificó que el tipo de sexismo que predomina es el sexismo ambivalente, ya que los hombres presentan actitudes sexistas significativamente más hostiles que las mujeres.

Palabras clave: estereotipos de género, sexismo, socialización de género, educación superior.

\section{Gender stereotypes and sexism among higher education professors}

\begin{abstract}
Gender socialization occurs on a daily basis and marks individual identity, as well as the culture of organizations and groups indelibly. The interaction between teachers and students is part of the gender socialization process. Thus, different research works have shown that the focus and the expectations the professors have vis-à-vis the students are different. The objective of this research was to analyze and characterize a group of Portuguese university professors, men and women, with regard to their gender stereotypes and sexism, in order to promote a joint reflection by the educators involved. Based on the results we were able to conclude that theseprofessors do have gender stereotypes, but with interesting distinctive features such as the fact that a higher load of instrumental traits is attributed to women. Likewise it was established that ambivalent sexism prevails, since men show significantly more hostile sexist attitudes than women.
\end{abstract}

Key words: gender stereotypes, sexism, gender socialization, higher education.

Recepción: 05/11/14. Aprobación: 03/06/15. 


\section{Introdução}

A socialização é o processo contínuo de aprendizagem da vida em sociedade e como tal engloba o conjunto de experiências e de mecanismos pelos quais uma pessoa se apropria da sua identidade e interioriza as normas e valores que lhe permitem entrar em relação com as outras pessoas e funcionar no seio de um grupo e, mais amplamente, da sociedade no seu todo (Giddens, 2010; Descarries e Mathieu, 2010). Neste processo os papeis de género ocupam um lugar proeminente relacionando o sexo biológico da pessoa com as expectativas sociais sobre a sua identidade de género. A chamada socialização de género inicia com as expectativas e tratamento diferenciais da família consoante o sexo do ou da bebé e processa-se ao longo de todo o percurso da vida do individuo Vieira (2006).

O sistema educativo é um dos principais agentes de socialização secundária; a escola é uma instituição central na sociedade ocidental contemporânea, tendo o papel fundamental de educar e escolarizar as novas gerações. A relação da escola com as alunas e os alunos é interpretada de forma distinta por diferentes autores e autoras. Assim, na perspetiva funcionalista, a escola é uma instituição neutra que difunde um conhecimento racional e objetivo e que seleciona os seus alunos e as suas alunas com base em critérios racionais. Esta perspectiva era dominante até que Bourdieu e Passeron lançam em 1970 o livro La Reproduction onde debatem os mecanismos de reprodução social nas instituições, nomeadamente na escola. Segundo estes autores, a escola é reprodutora de desigualdades porque é profundamente influenciada pelo contexto social circundante e pelo processo de socialização do seu pessoal - professores e professoras, funcionários e funcionárias - (Bourdieu e Passeron, 1978). No livro A Dominação Masculina Pierre Bourdieu (1999) explica a (re) produção dos papéis sociais de género e a persistência das relações de dominação a partir do conceito de habitus. A educação informal mediante um trabalho pedagógico de nominação, inculcação e incorporação, socializa as crianças para os papéis de género através de variadas e constantes estratégias educativas de diferenciação, na maior parte das vezes implícitas nas práticas de vários agentes e instituições como a família, a escola e os meios de comunicação. A produção teórica destes autores teve muito impacto ao nível da sociologia da educação e é hoje relativamente consensual a leitura de que as instituições educativas não são neutras.

O grupo profissional dos e das docentes é composto por indivíduos que ao longo do seu percurso de vida incorporaram valores e crenças através do processo de socialização que foram sendo alvo. Estes valores e crenças vão estar presentes no seu desempenho profissional e podem consequentemente estar presentes na sua relação com a discência.

Vários estudos empíricos apresentam resultados neste sentido, nomeadamente que as professoras e os professores "pela sua relação privilegiada [...] a as suas interações [...], linguísticas e pedagógicas com os estudantes, moldam em grande parte a representação que as raparigas e os rapazes fazem das relações entre mulheres e homens" (Project DAPHNE, 2008:2). ${ }^{1}$

"Nos diferentes trabalhos que exploram a relação entre docente-estudante durante a aula, parece claro que o pessoal docente faz parte do problema e da solução, e participa frequentemente, embora inconscientemente, por gestos, palavras ou comportamentos que reforçam os condicionamentos sexuais iniciados no seio da família" (Descarries e Mathieu, 2010: 53). Num estudo longitudinal de revisão de investigações sobre as atitudes dos professores e das professoras concluiu-se que estes são,

\footnotetext{
${ }^{1} \mathrm{O}$ "Manuel Pour la Formation des Enseignant-e-s à une Pedagogie Non-Sexiste" foi produzido no quadro do projeto piloto europeu "Formation des enseignant-e-s à une educatión non sexiste" do Programa DAPHNE. Fonte: [http://orientation.ac-clermont.fr/pmb/ opac_css/doc_num.php?explnum_id=150],consultado dezembro de 2012.
} 
sobretudo sexistas por omissão, ou seja, mais por aquilo que não fazem do que por aquilo que fazem. Adicionalmente, estão geralmente mais de acordo com políticas genéricas de igualdade de género, mas quando as mesmas se substantificam em atividades concretas expressam desacordo (García et al., 2011).

Outros estudos mostram que a atenção dada aos alunos e às alunas também está relacionada com a matéria ensinada. Segundo Marie Duru-Bellat "os professores e as professoras abordam os e as estudantes com expectativas estereotipadas. Os estereótipos de género povoam o espaço social e cultural das escolas, nas quais os professores e professoras dão maior atenção aos rapazes nas aulas de ciências e transmitem às raparigas baixas expectativas de sucesso nestas áreas" (Carmino, 2005: 24), outros autores como Leder (1996) e Magno e Silova (2007) partilham esta opinião. Leder (1987, 1995) confirma que as raparigas são objeto de menos interações e recebem menos encorajamento do que os rapazes nos cursos de matemática e Carmino observa que "os professores e as professoras que tentaram corrigir este desequilíbrio chegam com dificuldade a consagrar $45 \%$ do tempo às raparigas, e isto com um forte sentimento de favoritismo [...]" (Carmino, 2005: 25). Este tipo de interação reproduz as desigualdades de género, visto que as raparigas acabam por acreditar que são menos dotadas e que têm mais dificuldade nas matemáticas do que os rapazes. Isto pode ajudar-nos a entender o porquê de as carreiras científicas serem gendrificadas.

Os estereótipos são um conjunto de crenças estruturadas sobre as características dos membros de um determinado grupo. E os estereótipos de género definem-se como o conjunto de crenças sobre o que significa ser mulher ou homem incluindo informação sobre a aparência física, atitudes e interesses, traços psicológicos, relações sociais e actividades profissionais. Golombock e Fivush (1994). A informação que os estereótipos proporcionam combina simultaneamente a componente descritiva e a componente prescritiva; isto é, os estereótipos abrangem as crenças sobre como são homens e mulheres, e os comportamentos considerados socialmente adequados em função do sexo, em outras palavras "como devem ser e se comportar". Segundo Fiske e Stevens (1993) uma das particularidades dos estereótipos de género, em comparação com outros estereótipos, é precisamente o seu carácter prescritivo devido aos constantes e intensos contactos entre homens e mulheres. Nesta linha de pensamento Prentice e Carranza (2002) defendem que os estereótipos de género não são apenas prescritivos, mas também proscritivos; isto é, fazem referência às características adequadas segundo o sexo, mas também às não adequadas ou proibidas; a como "devem ser" e como "não devem ser" homens e mulheres. Segundo estes autores podem-se definir quatro categorias nos estereótipos de género em função da intensidade das prescrições e as proscrições:

- Prescrições intensificadas de género; são traços altamente desejados pela sociedade no geral, mas particularmente desejáveis para um sexo (homens corajosos e mulheres elegantes).

- Prescrições relaxadas de género; são qualidades consideradas socialmente como positivas, mas a sua ausência em um ou outro sexo não será considerada importante (num ambiente profissional não é julgada negativamente a mulher que não é ambiciosa).

- Proscrições intensificadas de género; são características pouco valorizadas socialmente e particularmente indesejáveis para um sexo (emotividade nos homens).

- Proscrições relaxadas de género; são traços pouco valorizados pela sociedade em geral, mas que não são censurados ou que podem ser valorizados em um dos sexos (é menos criticada a arrogância nos homens do que nas mulheres ou a ingenuidade é mais bem aceite no caso das mulheres). 
Os estudos de género têm dado enfase à desconstrução de estereótipos como forma de mudança de mentalidades e promoção da mensagem de igualdade de acesso e oportunidades entre homens e mulheres Ferreira (2010). Todavia o debate sobre a desconstrução de estereótipos não é consensual e há quem considere que este processo pode precisamente conduzir ao efeito contrário ao pretendido, ou seja, a desconstrução pode levar ao reforço Bernardes (2003). Todavia no nosso entender as culturas estabelecem as suas próprias definições de feminino e masculino focando o que significa ser homem ou ser mulher Vieira (2008) e o que deve fazer um homem e deve fazer uma mulher. Os valores culturais e as normas prevalentes em cada sociedade servem como guia e justificação das condutas do indivíduo, legitimando que homens e mulheres adotem determinados esquemas psicológicos, e ideológicos. Porém, é importante frisar que os estereótipos não são a causa direta das assimetrias de género existentes; as análises feministas demonstraram que é o sexismo e a discriminação sistemática o que estão na base da persistência das desigualdades de género Descarries e Mathieu (2010). Contudo os estereótipos permitem a formação de preconceitos relativos aos homens e mulheres que se podem traduzir em sexismo e que a difusão de ideias estereotipadas de género conduz com frequência a atitudes e posições sexistas. (Magalhães et al., 2007; Villas-Boas et al., 2014).

Segundo Glick e Fiske (1996; 2001), o sexismo é um conjunto de estereótipos que avaliam de forma cognitiva, afetiva e atitudinal os papéis apropriados aos indivíduos, em função do seu sexo. Existem dois tipos de sexismo: o sexismo hostil, que podemos entender como uma expressão inequívoca de preconceito em relação ao género, uma antipatia generalizada que reflete intolerância com relação aos papéis sexuais, baseados na imagem da mulher como um ser frágil e inferior e do homem como um ser forte e superior (Glik e Fiske, 1999; Glick, Lameiras e Castro, 2002; Formiga et al., 2002); e o sexismo benevolente, que se refere a uma atitude que muitas vezes é considerada não preconceituosa, pois assume uma postura protetora perante o indivíduo de acordo com o seu género, assim o homem é visto como provedor da família, cuja presença garante a proteção e o sustento da casa e a mulher é vista como a cuidadora (Glick e Fiske, 1999; Glick, Lameira e Castro, 2002; Formiga et al., 2002). Embora à primeira vista este tipo de sexismo pareça positivo, pois destaca a importância quer de homens quer de mulheres, na verdade continua a atribuir características e funções sociais aos indivíduos de acordo com o seu sexo e assim limitando o espectro individual de ação e reproduzindo desigualdades entre homens e mulheres. Este tipo de sexismo é muito mais difícil de combater visto que está implícita uma complementaridade de funções entre os dois sexos conduzindo ambos a acreditar num suposto equilíbrio natural ao nível social, familiar e emocional. Gilck e Fiske (1996) dicem que as atitudes sexistas justificam e reforçam a desigualdade entre os sexos e podem ser expressas de forma ambivalente, ou seja, por meio de atitudes tanto hostis como benevolentes perante o sujeito-alvo de preconceito.

Nas últimas décadas foram levadas a cabo diversas investigações com relação à presença de estereótipos de género no contexto educativo (Network, 2010; Schneeweis, and Zweimüller, 2012; Vieira, 2008), mas são ainda relativamente poucos os estudos que focam o contexto universitário (e especificamente no contexto universitário português não há estudos), sendo mais frequente o estudo desta problemática em níveis escolares mais iniciais. Na sua generalidade, quando o foco é colocado no contexto universitário, são estudados os estereótipos em relação aos e às docentes, como por exemplo, em Opre e Opre (2010) ou em De Garay e Valle-Dias-Munoz (2011) onde se abordam os estereótipos no contexto geral de questões de discriminação das mulheres em ambientes dominantemente masculinos, com processos de segregação horizontal e vertical associados. 
No presente estudo focamos os estereótipos e o tipo de sexismo dos e das docentes, porque a transmissão de estereotipias sexuais convencionais não se (re) produzem apenas por meio de mensagens explicitas, mas também por meio de mensagens implícitas dos modelos representados no contexto escolar, como é o caso do comportamento e atitudes dos e das docentes. Mesmo que os e as jovens não sejam meros imitadores de modelos, os estímulos e as expectativas exteriores compelem-nos a adotar comportamentos Assim a docência através de gestos, palavras ou comportamentos, muitas vezes inconscientes, podem fortalecer os condicionamentos sexuais. Sem podermos confirmar a transmissão dos estereótipos e o tipo de sexismo dos e das docentes questionados aos seus e suas às discentes - o que só poderia ser confirmado através da observação direta dos comportamentos e da interação na sala de aula o objetivo deste estudo exploratório é promover a reflexão dos e das docentes envolvidos no processo de aprendizagem de normas, vivências e de crescimento intelectual e pessoal que os e as estudantes fazem durante o período da sua formação académica. Pretende-se também destacar a importância da ação pedagógica da universidade na reprodução tradicional de modelos femininos e masculinos que tendencialmente conduzem a desigualdades de género no mercado do trabalho e nas restantes esferas da vida.

\section{Estudio empírico}

Este estudo decorreu na Universidade da Beira Interior (UBI) que é constituída por cinco faculdades: Faculdade de Ciências, Faculdade de Engenharias, Faculdade de Ciências Sociais e Humanas, Faculdade de Artes e Letras e Faculdade de Ciências da Saúde; distribuídas por quatro pólos na cidade da Covilhã, com quinze departamentos e 18 unidades de investigação. A sua composição, em 2011, era de 684 docentes (266 professoras e 418 professores), 280 funcionários e funcionárias não docentes e 6931 estudantes inscritas e/ou inscritos.
O estudo que aqui apresentamos esteve integrado num projecto mais vasto de diagnóstico de género em que a universidade esteve envolvida no âmbito do projeto UBIgual-Plano de Igualdade de Género da UBI.

A UBI foi a primeira universidade pública portuguesa a desenvolver um Plano de Igualdade de Género, em 2009. O diagnóstico de género que se levou a cabo procurou envolver toda a comunidade académica, docentes, trabalhadores e trabalhadoras não docentes e discentes. O estudo dos estereótipos de género e sexismo em docentes foi um estudo exploratório, realizado através da aplicação de um inquérito por questionário enviado via correio electrónico institucional a todas e todos os docentes, e disponível para preenchimento online durante os meses de outubro e novembro de 2010. Posteriormente foram feitas insistências via secretariado dos vários departamentos da universidade até ao final de dezembro, data em que se fechou a fase de recolha de dados.

\section{Amostra}

Participaram deste estudo 102 docentes da UBI, dos quais (n=66) 64.7\% são homens e (n=36) 35.3\% mulheres. A composição por faculdades é a seguinte: 35.3\% pertencem à faculdade de Ciências; 32.4\% à faculdade de Engenharias; 19.6\% à faculdade de Ciências Sociais e Humanas; $3.9 \%$ à faculdade de Ciências da Saúde e $8.8 \%$ à faculdade de Artes e Letras. Os e as respondentes abrangem 15\% da população-alvo da UBI, a saber, 684 docentes. O preenchimento do questionário foi realizado por administração direta sendo os inquiridos e as inquiridas quem directamente preencheu as suas respostas. A amostra é considerada não probabilística, podendo ser definida como de conveniência, já que o questionário foi enviado a toda a docência e foram consideradas todas as pessoas que se dispuseram a colaborar; deste modo os resultados não são passíveis de generalização. Os dados foram tratados e analisados com o pacote estatístico IBM SPSS statistics 19. 


\section{Instrumento}

O questionário é composto por três blocos: um primeiro grupo de questões de carácter sociodemográfico (idade, sexo, faculdade e categoria profissional) para caracterização da amostra. Um segundo bloco composto pelo estudo dos estereótipos e que apresenta uma listagem de 60 traços de personalidade, comportamentos e competências que os inquiridos e as inquiridas associam aos homens, às mulheres ou a ambos. A listagem de características foi elaborada a partir das propostas de Amâncio (1994) e Féat e Salomon (1991); o critério de selecção de atributos procurou estar adequado à situação concreta de ensino-aprendizagem e contém um número equilibrado de defeitos e qualidades masculinas e femininas. Este conjunto de 60 atributos abarca as três dimensões principais dos estereótipos sexuais identificadas nos trabalhos sobre esta temática (Amâncio, 1994: 55): dimensão da expressividade-instrumentalidade, dimensão de dominância-submissão e da sociabilidade e competência. Segundo o autor os estudos de estereótipos tomam como critério de consenso o $75 \%$ das respostas dentro de cada um dos grupos definidos, neste caso entre os homens e entre as mulheres para considerar como feminino ou masculino um traço de personalidade.

No presente trabalho optámos por reduzir esta exigência para $60 \%$ pelo facto de termos optado por adicionar a opção ambos. A introdução desta opção de resposta faz com que a obtenção de consenso alargado seja mais difícil já que dispersa as respostas e induz posicionamentos mais neutros. Apesar dos problemas expostos, optámos por introduzir esta opção de resposta porque considerámos que a mesma tem a virtude de expressar um posicionamento de crença na equidade dos sexos no que concerne a determinados traços de personalidade. Para ultrapassar parcialmente a dispersão nas respostas gerada pela aderência a esta escolha neutra recorremos, além dos consensos acima referidos à análise das características que unanimemente homens e mulheres não atribuem nunca ou excepcionalmente a nenhum dos sexos, situação que denominaremos de consensos negativos ou passivos. O estudo dos consensos activos (quando mais do $60 \%$ dos e das docentes atribuem um traço a uma categoria) e passivos (quando menos do 3\% de inquiridos e inquiridas associam um traço a um ou outro sexo) permite-nos abordar os dois componentes do estereótipo: o descritivo, relativo as características próprias de cada sexo; e o componente normativo seja este prescritivo ou proscritivo, isto é as características que devem e não devem possuir e como devem se comportar homens e mulheres (Fiske e Stevens, 1993; Prentice e Carranza, 2002).

O último bloco do instrumento consiste no Inventário de Sexismo Ambivalente (ASI), instrumento que avalia duas dimensões do sexismo hostil e benevolente. Este instrumento, dividido em duas subescalas, foi desenvolvido e validado por Glick e Fiske (1996) e posteriormente adaptado à língua portuguesa por Ferreira (2004) e Magalhães et al., (2007). O instrumento original contém 22 itens, no entanto optámos por utilizar apenas 18 itens; pois quatro das questões resultaram ambíguas sendo eliminadas após o pré-teste aplicado a sete docentes da UBI (um de Ciências, tres de Engenharia, dois de Artes e Letras e um de Ciências Sociais e Humanas). Em cada item utiliza-se uma escala Likert com cinco opções de resposta, que apresenta os seguintes extremos: $1=$ discordo totalmente a $5=$ concordo totalmente.

\section{Analise dos dados}

$\mathrm{Na}$ análise dos estereótipos foi aplicado um teste de qui-quadrado para contrastar as percentagens de resposta para cada atributo segundo o sexo dos inquiridos e das inquiridas.

Com o objetivo de caracterizar o comportamento da amostra de docentes da UBI em relação ao sexismo ambivalente, procedeu-se inicialmente à verificação da fiabilidade da escala (ISA) e a confirmar 
a sua estrutura factorial (hostil e benevolente), para de seguida conhecer as pontuações na escala em função do sexo dos e das respondentes. Tal validação da escala através de análise factorial pareceu-nos pertinente por várias razões; a primeira foi o termos procedido à eliminação na fase do pré-teste de quatro dos 22 itens que compõem a ISA, a segunda o inventário que utilizámos foi validado no Brasil (Formiga, 2002; Ferreira, 2004) e consideramos que existem nuances na utilização da língua portuguesa nos dois países.

A adequabilidade da amostra para a utilização da análise factorial foi verificada pelos valores do teste de esfericidade Barlett que apresenta um $\chi 2791$ 178; p=0.000; e um índice de adequação razoável $(\mathrm{KMO}=0.787) .{ }^{2}$ Em relação à consistência interna o conjunto de itens da escala apresenta um valor no coeficiente alfa de Cronbach de 0.872, o que indica que está a medir de forma satisfatória o sexismo. A fiabilidade da escala é reforçada pelo fato de que as correlações item-total serem todas superiores a 0.35 (com a excepção do item 2), e com valores moderadamente elevados.

Para comprovar a estrutura bi-fatorial do Inventario de Sexismo Ambivalente referida na literatura, procedeu-se à realização, na nossa amostra, duma análise factorial de componentes principais com rotação varimax, com solução antecipada de dois factores e retendo apenas as cargas factoriais iguais ou superiores a 0.30. Esta solução permite identificar nitidamente uma estrutura bi-fatorial (sexismo hostil e benevolente) semelhante à descrita por Glick e Fiske (1996) e Ferreira (2004). Ambos os factores explicam conjuntamente o $46.6 \%$ da variância total e apresentam cargas factoriais elevadas. O primeiro fator, com um eigenvalue de 35.90 e responsável por $32.7 \%$ da variância inclui 10 itens relacionados com o sexismo hostil tais como: -As mulheres gostam de provocar os homens, -Com a desculpa da igualdade as mulheres procuram privilégios, -Quando as mulheres perdem queixam-se de ter sido discriminadas; e itens relacionados com a ideia de que as mulheres albergam obscuras intenções quando reivindicam mais poder ou de instrumentalizar a sua inferioridade. No que diz respeito ao índice de consistência interna calculado pelo alfa Cronbach, o fator hostil apresentou um valor de 0.878. Se olharmos para o contributo de cada item observamos que o item $n^{\circ} 17$ : -As mulheres gostam de provocar os homens é o que possui as correlações mais elevadas e contribui em maior medida para a confiabilidade da subescala, pois o alfa desce visivelmente quando este item é eliminado da escala.

O segundo factor reúne os restantes oito itens associados ao sexismo benevolente, com um eigenvalue de 2.49 , responsável por $19.6 \%$ da variância total. Inclui os aspetos que Glik e Fiske (1996) denominam gender differentiation, onde destaca a ideia do valor das mulheres como complemento em relação aos homens: -O homem não é verdadeiramente homem se não tiver o amor de uma mulher, -Os homens não são verdadeiramente completos sem as mulheres, e estereótipos positivos tipicamente femininos tais como: -O bom gosto das mulheres ou -As mulheres tem uma pureza que poucos homens possuem.

Em relação à consistência interna da subescala benevolente, o valor do alfa de Cronbach é aceitável 0.796, sendo que o item 18: -As mulheres devem ser amadas e protegidas é o que menos contribui, pois contém as correlações mais baixas, embora superiores a 0.35 , o alfa não desce sensivelmente quando este item é retirado da escala.

\section{Resultados \\ Estereótipos de gênero}

Numa primeira análise das frequências das respostas, verifica-se que os consensos mais alargados ficam concentrados na opção ambos o que vem

\footnotetext{
${ }^{2}$ Critérios de ajuste de teste KMO segundo as indicações de Pestana e Gageiro (2005).
} 
dar-nos a representação da noção de pessoa adulta caracterizada por ter: inteligência, competência, personalidade forte e responsabilidade Amâncio (1992); traços que apresentam percentagens superiores aos $60 \%$ nas e nos docentes. Com resposta de $58 \%$ das mulheres e acima dos $70 \%$ nos homens aparece: trabalho, eficiência e ambição. Todas estas características, conotadas habitualmente como positivas, estão associadas à esfera do trabalho; a maioria é de carácter nitidamente instrumental, destacando-se os elementos de dominância e autonomia. Na listagen de características com percentagens de resposta superiores ao 50\% para a opção "ambos" dos e das docentes (tabela 1), podemos verificar que existem percentagens superiores nos homens, que tendem a escolher mais do que as mulheres a opção "ambos" e uma elevada unanimidade nas características atribuíveis a ambos os sexos, que coincidem em 15 dos 20 atributos apresentados na tabela. Em termos gerais, os e as respondentes também atribuem a ambos, qualidades positivas da dimensão de sociabilidade (atenção, amabilidade, generosidade) aparecendo apenas dois traços relacionados com a dimensão de dependência - submissão (influenciável e indecisão).

Portanto a representação que as e os docentes têm de um individuo adulto responde a um conjunto de características quase exclusivamente positivas ligadas à dimensão instrumental o que revela a importância que este grupo de homens e mulheres docentes outorgam ao trabalho como elemento primordial no ideal de pessoa adulta. A novidade em relação aos estudos de Amâncio é a menor presença e menor consenso, no ideal de adulto, em relação a características ligadas à sociabilidade (amabilidade, generosidade). Estes resultados espelham um adulto mais instrumental e menos expressivo, mais competente e menos sociável.
Em relação aos consensos sobre as características consideradas femininas, destacam-se três atributos: emotividade, organização e cuidar dos outros, seguidos de um grupo de características relacionadas com qualidades também expressivas, tais como: elegância e sentimentalismo. Portanto as características atribuídas à feminidade afastam-se da representação do individuo adulto (ambos) tipicamente instrumental, que vimos mais acima; a feminilidade é definida pelos e pelas docentes pela sua expressividade, a importância da aparência física elegante o que não tem um correlato no estereótipo masculino e também pela função tradicional de cuidadora. É de sublinhar uma considerável auto-atribuição por parte das mulheres de um conjunto de traços negativos que tradicionalmente compõem a feminidade tais como: submissão, fragilidade e nomeadamente no caso da sensibilidade que elas adjudicam expressivamente $^{3}$ mais à feminidade e os homens outorgam mais a $\operatorname{ambos}\left(\chi^{2}=7.754, \mathrm{GL}=3, \mathrm{p}=0 \mathrm{w} .005\right)$. Esta assunção dos traços tradicionalmente femininos pelas próprias mulheres é percetível quando olhamos para o ranking de características que obtiveram entre elas pelo menos $50 \%$ de respostas.

Na tabela 2 verifica-se certo consenso na definição da feminidade baseada nos aspectos expressivos conotados como positivos (emotividade, sentimentalismo, romantismo, ou os conotados como negativos da dimensão de sociabilidade (fofoquice, submissão e fragilidade); mas também uma feminidade que reclama a capacidade para gerir e planificar). Verifica-se ainda que as mulheres tendam a introduzir no retrato da feminidade elementos mais instrumentais como o sentido prático, o perfeccionismo, adaptabilidade e dinamismo ao tempo que reforçam a orientação para desempenhar o papel social tradicionalmente atribuído às mulheres como

\footnotetext{
${ }^{3}$ Quando nos referimos a diferenças significativas ou expressivas baseamo-nos na aplicação do teste de $\chi 2$ às distribuições das classificações (ambos , feminina, masculina e NS/NR)realizadas pelos homens e pelas mulheres, e cujos valores correspondem a níveis de significância elevados $(\mathrm{p}<0.05, \mathrm{gl}=3)$.
} 


\section{Tabela 1. Atribuição de estereótipos a homens e mulheres segundo o sexo}

\begin{tabular}{|c|c|c|c|}
\hline \multicolumn{2}{|c|}{ Mulheres } & \multicolumn{2}{|c|}{ Homens } \\
\hline Estereótipo & $\%$ & Estereótipo & $\%$ \\
\hline Inteligência* & 72.2 & Competência* & 86.4 \\
\hline Competência* & 69.4 & Inteligência* & 84.8 \\
\hline Personalidade forte* & 66.7 & Trabalho* & 77.3 \\
\hline Atenção & 66.7 & Generosidade & 74.2 \\
\hline Responsabilidade* & 63.9 & Dinamismo & 72.7 \\
\hline Indisciplina & 58.3 & Personalidade forte* & 71.2 \\
\hline Amabilidade & 58.3 & Responsabilidade* & 71.2 \\
\hline Trabalho* & 58.3 & Eficiência* & 71.2 \\
\hline Eficiência* & 58.3 & Ambição* & 69.7 \\
\hline Ambição* & 58.3 & Adaptabilidade & 65.2 \\
\hline Generosidade & 55.6 & Indecisão & 63.6 \\
\hline Dinamismo & 54.3 & Influenciável & 63.6 \\
\hline Coragem & 54.3 & Competitividade & 63.6 \\
\hline Dedicação & 52.8 & Interesse por aprender & 62.1 \\
\hline Interesse por aprender & 52.8 & Assertividade & 62.1 \\
\hline Autonomia & 52.8 & Determinação & 59.1 \\
\hline Influenciável & 52.8 & Dedicação & 59.1 \\
\hline Rebeldia & 52.8 & Autonomia & 57.6 \\
\hline Determinação & 50.0 & Teimosia & 56.9 \\
\hline Imprevisibilidade & 50.0 & Coragem & 56.1 \\
\hline
\end{tabular}

(*) Traços de Personalidade, comportamentos e competências consensuais.

cuidadoras (cuida e protege aos outros). A visão dos homens sobre a feminidade mantém-se nos moldes tradicionais da expressividade e sociabilidade, embora as percentagens de atribuição sejam menores do que nas mulheres, pois como já foram referidos, os homens tendem a concentrar as suas respostas na opção: ambos.
A construção social de género envolve aspetos descritivos e normativos, ou seja, outorga e nega atributos e determina o que as mulheres e os homens devem ou não devem fazer. Por esta razão, para além de se analisarem os consensos positivos, importa analisar os consensos negativos.

Assim, olhando para os consensos negativos ou 
passivos, isto é, para aquelas características que nunca ou raramente são associados por ambos os sexos às mulheres, observamos alguns traços de personalidade particularmente negativos quando aplicados à população estudantil. Por exemplo, os e as docentes concordam em que não ter hábitos de estudo, indisciplina, preguiça, imaturidade e desorganização, não são características femininas. Retomando a ideia da dimensão prescritiva do estereótipo, poder-se-ia inferir que das mulheres é expectável um comportamento que não se adequa ao de má estudante. ${ }^{4}$

Em relação aos estereótipos masculinos, o que primeiro chama a atenção é a ausência de amplos consensos, que se traduz num menor número de

Tabela 2. Atribuição dos estereótipos como femininos segundo o sexo

\begin{tabular}{|c|c|c|c|}
\hline \multicolumn{2}{|c|}{ Mulheres } & \multicolumn{2}{|c|}{ Homens } \\
\hline Estereótipo & $\%$ & Estereótipo & $\%$ \\
\hline Emotividade* & 75.0 & Emotividade* & 68.2 \\
\hline Cuidado dos outros* & 69.4 & Organização* & 57.6 \\
\hline Sensibilidade & 69.4 & Cuidado dos outros* & 56.1 \\
\hline Organização* & 66.7 & Fofoquice* & 53.0 \\
\hline Elegância* & 63.9 & Delicadeza & 51.5 \\
\hline Sentido prático & 58.3 & Elegância* & 51.5 \\
\hline Fofoquice* & 52.8 & Romantismo & 50.0 \\
\hline Protege aos outros & 52.8 & Sentimentalismo & 48.5 \\
\hline Sentimentalismo & 52.8 & Meiguice & 47.0 \\
\hline Perfeccionismo & 50.0 & Fragilidade & 47.0 \\
\hline Submissão & 50.0 & Aplicação & 43.9 \\
\hline Romantismo & 50.0 & Vaidade & 43.9 \\
\hline Fragilidade & 50.0 & Sensibilidade & 42.4 \\
\hline Indisciplina & 2.8 & Preguiça & 3.0 \\
\hline Desorganização & 2.8 & Desorganização & 1.5 \\
\hline Imaturidade & 2.8 & Imaturidade & 1.5 \\
\hline Sem hábitos de estudo* & 0 & Indisciplina & 0 \\
\hline Preguiça & 0 & Sem hábitos de estudo* & 0 \\
\hline
\end{tabular}

(*) Traços de Personalidade, comportamentos e competências consensuais.

\footnotetext{
${ }^{4}$ Amâncio mostrou num estudo sobre tomada de decisões em contexto organizacional, que os estereótipos contribuem para imprimir um significado masculino ou feminino aos comportamentos, e que os conteúdos simbólicos dos estereótipos eram normativos apenas para as mulheres "porque é no caso delas que os juízos são orientados por expectativas de adequação ou não adequação dos seus comportamentos às fronteiras delimitadas pelos estereótipos” (1992, p.17).
} 
traços de personalidade considerados como unanimemente masculinos; seguido do fato destes traços serem na sua maioria conotados negativamente. $\mathrm{Na}$ tabela 3 apresentam-se ordenadas as 10 características que possuem as percentagens mais elevadas, isto é os traços que homens e mulheres consideram em maior medida como masculinos, e as 10 que reuniram as percentagens mais baixas, ou seja, aquelas que não são atribuídas nunca ou raramente como masculinas. Como se pode apreciar nesta tabela, apenas uma característica, a de desorganização, consegue reunir o consenso dos $60 \% \mathrm{em}$ ambos os sexos, sendo que, correr riscos é selecionada por metade das mulheres e dos homens. Note-se que ainda que nas duas colunas coincidam seis das 10 características (desorganização, imaturidade, correr riscos, sem hábito de estudo, agressividade e indisciplina), nos restantes atributos existe uma visão ligeiramente divergente entre os sexos. Para as mulheres, que tendem no geral a classificarem os traços como mais masculinos ou femininos e menos como neutros, a masculinidade está associada a características de dominância como autoritarismo, agressividade e exibicionista.

Enquanto os homens reclamam timidamente para a sua categoria quatro traços mais positivos: sentido prático, racionalidade, liderança e audácia, todos eles pertencentes à dimensão instrumental. Embora a representação da masculinidade que constroem as docentes é mais negativa do que a autoimagem que referem os docentes, é preciso lembrar que as conotações valorativas de alguns atributos variam conforme o sexo podendo ser consideradas positivas para um sexo (prescritivas) e negativas para o outro (proibitivas). Assim, segundo os estudos de estereótipos algumas destas qualidades, quando atribuídas aos homens não são conotadas negativamente, é o caso da categoria autoritarismo ou correr riscos que são consideradas neutras.

Se olharmos para os consensos negativos, verificamos que ninguém associa com a masculinidade dois atributos instrumentais relativos à ética do trabalho, responsabilidade e competência, o que resulta surpreendente dado que estas características positivas têm sido associadas tradicionalmente aos homens. Coincidem também homens e mulheres em não associar à masculinidade a caracteristicas tais como à elegância e a emotividade, que, como foi referido anteriormente, foram categorizados maioritariamente como femininos. Os restantes traços que não são associados unanimemente à masculinidade dizem respeito tanto a dimensões emotivas tais como romantismo, dedicação, vaidade e fofoquice, como a dimensões instrumentais, trabalho, eficiência e organização.

De acordo com estes resultados ter-se-á operado uma mudança no estereótipo masculino no sentido de reduzir o número de atributos e nomeadamente, uma alteração na carga valorativa dos mesmos que tende a ser mais negativa.

Para além dos consensos referidos, evidencia-se uma disputa entre os sexos em relação a alguns traços que ilustram o rumo da mudança operada nos estereótipos femininos e masculinos. Na procura das diferenças significativas na atribuição (ambos, feminino e masculino) segundo o sexo dos docentes apresenta-se, na tabela 4, os valores de significação para cada um dos estereótipos realizados através do teste de qui- quadrado.

Em primeiro lugar observa-se uma atribuição simétrica e complementar no sentido prático, a racionalidade e a coragem, pois ambos se advogam essas características. Elas consideram-nas significativamente mais como femininas e menos como masculinas, enquanto eles as atribuem mais como masculinas e menos como femininas. Os resultados do teste de qui- quadrado para cada traço foram os seguintes: sentido prático $\chi 2=13.91, \mathrm{GL}=3$, $\mathrm{p}=0.000 ;$ racionalidade $\chi^{2}=11.71, \mathrm{GL}=3, \mathrm{p}=.008$; coragem $\chi 2=20.20, \mathrm{GL}=3, \mathrm{p}=0.000$. Uma luta por adquirir no caso das mulheres e de manter no caso dos homens um conjunto de traços, todos eles 
instrumentais e conotados positivamente, que como foi referido anteriormente são aqueles que definem o adulto ideal. Um segundo grupo de traços composto por adaptabilidade, dinamismo, generosidade e sensibilidade é reivindicado pelas mulheres para sua própria categoria, enquanto os homens tendem a atribuir-lhas significativamente mais a ambos $\left(\chi 2=16.70, \mathrm{GL}=3, \mathrm{p}=0.001 ; \chi^{2}=12.35, \mathrm{GL}=3\right.$, $\mathrm{p}=0.006 ; \quad \chi^{2}=9.366 . \quad \mathrm{GL}=3, \mathrm{p}=0.025 ; \chi^{2}=7.754$,
$\mathrm{GL}=3, \mathrm{p}=0.005$, respectivamente). Note-se que este conjunto de características pertence às dimensões expressivas e de sociabilidade e são todas consideradas qualidades positivas. Por último aparecem dois traços de sociabilidade conotados negativamente: teimosia e imprevisibilidade que as mulheres atribuem significativamente mais como masculinos e os homens a ambos $(\chi 2=11.874, \mathrm{GL}=3, \mathrm{p}=0.008$; $\chi 2=8.289, \mathrm{GL}=3, \mathrm{p}=0.040$, respectivamente).

Tabela 3. Atribuição dos estereótipos como masculinos segundo o sexo

\begin{tabular}{|c|c|c|c|}
\hline \multicolumn{2}{|c|}{ Mulheres } & \multicolumn{2}{|c|}{ Homens } \\
\hline Estereótipo & $\%$ & Estereótipo & $\%$ \\
\hline Desorganização* & 61.1 & Desorganização* & 60.6 \\
\hline Imaturidade & 55.6 & Correr riscos* & 47.0 \\
\hline Correr riscos* & 52.8 & Sentido prático & 43.9 \\
\hline Sem hábitos de estudo & 47.2 & Agressividade & 43.9 \\
\hline Agressividade & 44.4 & Imaturidade & 36.4 \\
\hline Autoritarismo & 41.7 & Racionalidade & 34.8 \\
\hline Exibicionista & 38.9 & Indisciplina & 31.8 \\
\hline Interesses fora da escola & 36.1 & Sem hábitos de estudo & 31.8 \\
\hline Desinibição & 36.1 & Liderança & 31.8 \\
\hline Indisciplina & 30.6 & Audácia & 30.3 \\
\hline Submissão & 2.8 & Atenção & 3.0 \\
\hline Inteligência & 2.8 & Sensibilidade & 3.0 \\
\hline Romantismo & 2.8 & Organização & 1.5 \\
\hline Eficiência & 2.8 & Emotividade & 1.5 \\
\hline Responsabilidade* & 0 & Fofoquice & 1.5 \\
\hline Dedicação & 0 & Vaidade & 1.5 \\
\hline Protege aos outros & 0 & Trabalho & 1.5 \\
\hline Competência* & 0 & Elegância & 1.5 \\
\hline Sensibilidade & 0 & Responsabilidade* & 0 \\
\hline Elegância & 0 & Competência* & 0 \\
\hline
\end{tabular}

(*) Traços de Personalidade, comportamentos e competências consensuais. 


\section{Tabela 4. Cargas fatoriais e comunalidadesdas subescalas de sexismo ambivalente}

\begin{tabular}{|c|c|c|}
\hline Sexismo benevolente & Carga factorial & Comunalidades \\
\hline $\begin{array}{l}\text { Não importa o quanto seja realizado, o homem não é verdadeiramente homem se não tiver o } \\
\text { amor de uma mulher }\end{array}$ & 0.774 & 0.642 \\
\hline Os homens não são totalmente completos sem as mulheres & 0.681 & 0.505 \\
\hline Muitas mulheres têm uma pureza que poucos homens possuem & 0.664 & 0.442 \\
\hline As mulheres costumam ter mais sensibilidade moral do que os homens & 0.644 & 0.448 \\
\hline As mulheres costumam ter mais bom gosto e uma cultura mais refinada que os homens & 0.589 & 0.459 \\
\hline $\begin{array}{l}\text { O homem deve estar disposto a fazer sacrifícios para satisfazer as necessidades financeiras } \\
\text { da sua mulher }\end{array}$ & 0.579 & 0.347 \\
\hline Num desastre, as mulheres devem ser salvas antes dos homens. & 0.570 & 0.348 \\
\hline As mulheres devem ser amadas e protegidas pelos homens & 0.499 & 0.269 \\
\hline Sexismo hostil & Carga factorial & Comunalidades \\
\hline $\begin{array}{l}\text { As mulheres gostam de provocar os homens, parecendo estar disponíveis para depois } \\
\text { recusar os convites masculinos. }\end{array}$ & 0.821 & 0.676 \\
\hline Muitas mulheres com a desculpa da igualdade, o que procuram são privilégios. & 0.717 & 0.514 \\
\hline $\begin{array}{l}\text { Quando as mulheres perdem para os homens numa competição justa, elas em geral } \\
\text { queixam-se de ter sido discriminadas }\end{array}$ & 0.689 & 0.477 \\
\hline As mulheres exageram os problemas que têm no trabalho & 0.675 & 0.469 \\
\hline As feministas querem é que as mulheres tenham mais poder que os homens & 0.672 & 0.477 \\
\hline A maioria das mulheres interpreta observações ou actos inocentes como discriminatórios & 0.660 & 0.481 \\
\hline As mulheres ofendem-se muito facilmente. & 0.643 & 0.463 \\
\hline A maioria das mulheres não avalia plenamente tudo o que os homens fazem por elas & 0.642 & 0.455 \\
\hline Quando uma mulher conquista um homem ela costuma mantê-lo sob-rédea curta & 0.620 & 0.402 \\
\hline As mulheres querem obter poder para exercer controlo sobre os homens & 0.601 & 0.518 \\
\hline
\end{tabular}




\section{Escala de sexismo ambivalente}

Com o intuito de conhecer o comportamento da escala de sexismo ambivalente em função do sexo das pessoas inquiridas, procedeu-se ao apuramento da correlação entre as pontuações obtidas nas duas subescalas (hostil e benevolente) separadamente para a amostra de homens e de mulheres. Os resultados do coeficiente de correlação de Pearson mostram a presença de correlações positivas significativas $(\mathrm{r}=0.380 ; \mathrm{p}<0.05$ na amostra feminina e $\mathrm{r}=0.383$ $\mathrm{p}<0.01$ na amostra masculina). Esta associação entre os dois tipos de atitudes sexistas indica que ambas formam parte do mesmo sistema ideológico e que ambas contribuem para a manutenção dos padrões sexuais tradicionais. O sexismo benevolente estaria a legitimar o sexismo hostil passando a ideia de que os homens não dominam as mulheres, mas ao contrário as protegem, admiram e complementam (Ferreira, 2004: 125).

Uma vez verificada a existência de correlação procurou-se conhecer as possíveis diferenças nas pontuações médias obtidas nas duas subescalas segundo o sexo. Para tal foi aplicado o teste $t$ para amostras independentes que permitiu comparar as médias obtidas pelas mulheres e pelos homens em cada um dos factores do sexismo ambivalente (hostil e benevolente). Como se pode apreciar na tabela 5 os homens apresentam valores médios mais elevados do que as mulheres em ambos os factores do sexismo ambivalente e consequentemente na escala total, porém as diferenças são estatisticamente significativas apenas no sexismo hostil e na escala global.

Exploraram-se também as diferenças entre os dois factores do sexismo ambivalente para cada sexo separadamente, com o objectivo de verificar se as pontuações mais elevadas no sexismo hostil são significativas em ambos os sexos. O teste $t$ para amostras pareadas indica diferenças significativas estatisticamente apenas no caso dos homens $(\mathrm{t}=2$ 769; $\mathrm{p}=0.007)$. Isto é, no caso dos docentes os valores médios do sexismo hostil são expressivamente superiores aos do sexismo benevolente. Estes resultados apontam a existência entre os docentes da amostra de níveis mais elevados de sexismo, nomeadamente do sexismo hostil, em comparação com as suas colegas.

Tabela 5. Médias, desvio padrão e estatística t-Student na escala de sexismo
ambivalente e os seus factores segundo o sexo

\begin{tabular}{|c|c|c|c|c|c|c|c|}
\hline & \multicolumn{2}{|c|}{ Mulheres } & \multicolumn{2}{|c|}{ Homens } & \multirow[b]{2}{*}{$t$} & \multirow[b]{2}{*}{$G L$} & \multirow[b]{2}{*}{ Sig. } \\
\hline & $M$ & $D P$ & $M$ & $D P$ & & & \\
\hline Ambivalente & 2.70 & 0.57 & 2.43 & 0.61 & -2227 & 100 & $0.028 *$ \\
\hline Hostil & 2.81 & 0.64 & 2.51 & 0.78 & -1984 & 100 & $0.049 *$ \\
\hline Benevolente & 2.55 & 0.69 & 2.31 & 0.64 & -1687 & 100 & 0.095 \\
\hline
\end{tabular}

(*) Traços de Personalidade, comportamentos e competências consensuais. 
Em termos de prevalência dos dois tipos de sexismo segundo o sexo, entre os homens verificou-se uma maior prevalência do sexismo hostil $36.4 \%$, face aos $19.7 \%$ de sexistas benevolentes; por sua vez entre as mulheres $19.4 \%$ foram sexistas hostis e $8.3 \%$ benevolentes. Note-se que foram sexistas sensivelmente metade dos docentes $56.1 \%$ em face de apenas $27.7 \%$ das docentes, mas que para ambos os sexos o sexismo hostil é a forma preponderante. Apesar das mulheres inquiridas se terem mostrado menos sexistas do que os homens o sexismo hostil atinge entre elas quase $20 \%$ o que remete a existência de um grupo de professoras com atitudes tradicionais em relação à posição das mulheres na sociedade, e mesmo pertencendo a um grupo de mulheres que tem atingido elevadas quotas de igualdade na esfera pública.

Os resultados destes dois estudos (estereótipos e escala de sexismo ambivalente) permitem mostrar mudanças na visão estereotipada de género no sentido de uma paulatina diminuição nas diferenças nos estereótipos de género entre homens e mulheres. Estas mudanças estão provavelmente relacionadas com as mudanças sociais levadas a cabo nos últimos 30 anos na sociedade portuguesa, mas também com a posição estrutural específica que os e as docentes inquiridas ocupam, isto é com o contexto universitário em que desenvolvem as suas vidas profissionais. Por um lado observa-se uma confluência de atributos nas características da esfera social (nomeadamente instrumentais e de competência) e por outro lado, mantém-se a importância do aspecto físico na definição da feminidade (elegância) por ambos. Destaca-se, porém que esta confluência nos estereótipos de género é assimétrica, as mulheres incorporam muitos traços tradicionalmente atribuídos como masculinos, enquanto os homens incorporam poucos femininos. Por último, é de frisar que o teor avaliativo dos estereótipos associados às mulheres é mais positivo do que dos homens.

\section{Discussão}

Em relação aos resultados sobre os estereótipos de género, o que chama a atenção é que existem poucos traços de personalidade unanimemente atribuídos aos homens e que os que lhes são adjudicados são negativamente valorizados (desorganização, imaturidade, correr riscos, sem hábito de estudo, agressividade e indisciplina). Os resultados retratam uma masculinidade com poucos atributos específicos e em que os traços instrumentais que tipicamente lhe eram próprios (responsabilidade, trabalho $\mathrm{e}$ competência) são agora partilhados com as mulheres. Este resultado contrasta com alguns estudos anteriores, nomeadamente Amâncio (1992, 1994), que refere como habitual nos estudos de estereótipos a identificação de um maior número de atributos masculinos, e por tanto menos características tipicamente femininas; e mais traços positivos associados à masculinidade. Estes resultados são, porém coerentes com a tendência exposta por Eagly e Mladinic (1994), que aludem a um paulatino aumento de atributos favoráveis para as mulheres devido em parte à persistência do estereótipo da feminidade associada à expressividade e comunhão com os outros. ${ }^{5}$

No estereótipo feminino perdura a associação com uma função social, um papel específico que aponta a maternidade, a cuidar dos outros. "A representação do feminino define um ser contextualizado no espaço privado da família e dos sentimentos, enquanto o masculino é representado como um ser universal" (Amâncio 1992: 20). A conjugação no estereótipo da feminidade de atributos instrumentais ligados ao âmbito laboral com a persistência do papel de cuidadora pode ser entendida como um reflexo da situação de dupla jornada das mulheres que

\footnotetext{
${ }^{5}$ Não podemos comparar diretamente estes resultados com os estudos citados, pois foram utilizadas opções metodologicas diferentes, concretamente estes estudos não incluem a opção neutra e pedem aos inquiridos e às inquiridas para efetuar uma valorização dos traços.
} 
trabalham. Os estereótipos femininos e masculinos continuam a serem, até certo ponto, complementares e excludentes, no sentido de que o que é atribuído como feminino não é masculino e vice-versa.

A tendência geral parece ser que a feminidade incorpora traços instrumentais considerados positivos e tradicionalmente masculinos, sem perder os atributos emocionais e a masculinidade parece perder alguns dos atributos instrumentais. Assim observa-se um progressivo esvaziamento dos traços positivos atribuídos aos homens que são, em boa medida, apropriados pelas mulheres, ficando a masculinidade com algumas características conotadas negativamente. Esta mudança é coerente com a reconfiguração das relações de poder entre homens e mulheres e a emergência de novas feminidades e masculinidades (Wall et al., 2010; Aboim e Vasconcelos, 2012). É de sublinhar que os homens inquiridos tendem mais a escolher a opção ambos provavelmente devido a mudança nas relações de poder entre sexos e a sua localização no contexto universitário. Podemos interpretar estes dados à luz da mudança social e do contexto universitário, instituição que se está a feminizar INE (2012); Chagas Lopes e Perista (2010), e que formalmente é regida pela meritocracia e onde as mulheres têm atingido níveis de igualdade mais elevados em relação a outros âmbitos como o doméstico (Oliveira et al., 2010; Carvalho et al., 2012). A percepção intergrupal, que é dependente das relações estruturais entre os grupos, parece ser o grupo tradicionalmente desfavorecido (as mulheres) está em processo de transformação atingindo maiores quotas de poder e estas elaboram por isso uma auto-representação carregada de atributos positivos; por outro lado, o grupo com estatuto elevado (os homens) responde a estas alterações com a neutralidade (opção politicamente correta ambos), mas também com elevados níveis de sexismo ambivalente em relação às mulheres.

As maiorias das características consensuais na opção ambos estão associadas ao mundo do trabalho e fazem parte da dimensão instrumental o que para uma amostra de docentes do ensino superior pode ser o reflexo por um lado da sua experiência profissional, na que não pode ser obviada a presença maioritária das mulheres na universidade; e por outro lado, mudanças estruturais como a já longa e expressiva presença das mulheres no mercado de trabalho português desde os anos sessenta do século passado.

A listagem de traços de personalidade incluiu uma série de defeitos e qualidades relacionados com o desempenho académico tais como: interesse por aprender, preguiça, responsabilidade, inteligência, indisciplina, ter mais interesses fora da escola, sem hábitos de estudo, entre outros. A análise revela alguns resultados relevantes sobre os estereótipos de género que os e as docentes partilham em relação às expectativas de comportamento dos e das estudantes. Nunca ou muito raramente são associados à feminidade defeitos estudantis, tais como: sem hábitos de estudo, preguiça, imaturidade e desorganização, mas são atribuídos à masculinidade alguns destes defeitos como: desorganização e sem hábito de estudo. Estes resultados parecem estar na mesma linha das tendências gerais ao nível dos estereótipos femininos Vieira (2008) que associam à mulher a capacidade de (se) organizar e a maturidade oriundas da sua função cuidadora.

Em relação ao comportamento dos e das docentes inquiridos e das inquiridas perante a escala de sexismo ambivalente é de salientar, por um lado, uma pontuação significativamente superior dos homens na subescala de sexismo hostil, o que aponta resultados semelhantes aos obtidos por Ferreira (2004) com uma amostra de estudantes brasileiros e brasileiras. Por outro lado, a ausência de diferenças significativas entre homens e mulheres no sexismo benevolente parece indicar que estas docentes assumem facilmente este tipo de sexismo. Assim, as mulheres rejeitam as formas mais evidentes de sexismo hostil, mas não as formas benévolas, admitindo assim o embuste da complementaridade entre os 
sexos que, segundo Glick e Fiske (1996), se deve às supostas vantagens que o paternalismo e os estereótipos positivos parecem trazer as mulheres. Neste sentido, é de sublinhar que a imagem estereotipada da feminidade como expressiva e orientada para os outros se conforma em grande medida a partir da auto-atribuição (logo aceitação) por parte das próprias docentes e em menor medida dos docentes. Esta aceitação do sexismo benevolente por parte dos e das docentes é congruente com o conjunto de estereótipos femininos que maior consenso reuniram que são precisamente traços positivos expressivos relacionados com as afirmações benevolentes da escala as mulheres são refinadas, sensíveis.

$\mathrm{O}$ facto de os sexismos hostil e benevolente estarem positivamente correlacionados reforça a ideia defendida por (Ferreira, 2004: 124) de que ambas as formas de sexismo fazem parte do mesmo sistema de recompensas e punições aplicadas diferencialmente segundo as posições na hierarquia de género. Se recordarmos que o sexismo benevolente tende a ser mais bem tolerado porque é confortável para ambas as partes e, por isso, mais complexo de combater (Barreto e Ellemers, 2005) podemos considerar que estamos perante um processo de encadeamento dos dois tipos de sexismo que certamente dificulta a implementação de um ambiente de real igualdade de género.

\section{Conclusão}

A educação escolar não discriminatória é uma ferramenta fundamental para a promoção da igualdade de género nas sociedades atuais. Assim, a universidade tem um papel relevante não só como agente educador, mas sobretudo como agente para a mudança.

Deste modo, urge promover a reflexão sobre a ação pedagógica da universidade na reprodução tradicional de modelos femininos e masculinos que tendencialmente conduzem a desigualdades de género no mercado do trabalho e nas restantes esferas da vida. Dos resultados obtidos neste estudo concluímos que as e os docentes respondentes apresentam estereótipos de género, mesmo que com algumas peculiaridades, tais como às mulheres serem atribuídas, sobretudo pelas docentes, características mais instrumentais do que é usual no modelo dito tradicional de divisão de papéis sociais. Mas o que por um lado parece ser um sinal de maior aceitação da competência das mulheres, por outro lado, pode ser apenas a continuidade da tendência de a igualdade de género ser um assunto de mulheres no qual os homens continuam a não fazer a sua parte Connell (2003).

Comprovou-se igualmente que as atitudes sexistas deste grupo são ambivalentes, ou seja, oscilam entre as atitudes sexistas hostis (mais representadas no grupo de docentes masculinos do que femininos) e as atitudes benevolentes.

Estes resultados foram apresentados no âmbito do plano de igualdade de género da UBI à comunidade académica e mais especificamente ao grupo da docência. Desta experiência ficou claro que os docentes e as docentes não são conscientes dos estereótipos de género e possíveis atitudes sexistas pelo que olham com muita desconfiança estes resultados. Deste modo consideramos que a universidade deveria levar a cabo uma investigação por observação direta no contexto de sala de aula, uma investigação que documentasse não só os comportamentos diferenciais na interação docente-discente como também que comparasse os mesmos com os resultados do presente trabalho. Parece-nos evidente que enquanto o corpo docente continuar em negação sobre a influência que os seus estereótipos e as suas atitudes sexistas podem ter na sua discência não há condições para promover a necessária reflexão quer intrínseca quer em grupo para que haja uma mudança efetiva. Como é lógico, se não aceitarem esta possibilidade não utilizarão estratégias sensíveis às questões de género nas suas aulas pelo que tendencialmente o status quo manter-se-á contrariando os objectivos de uma mudança organizacional em prol da igualdade de género. 


\section{Referencias}

Aboim, S. e P. Vasconcelos (2012), Study on the Role of Men in Gender Equality in Portugal, Estudos e Relatórios 3, Lisboa, Instituto de Ciências Sociais.

Amâncio, L. (1992), "As assimetrias nas representações do género", en Revista Crítica de Ciências Sociais, núm 34, pp. 9-22.

Amâncio, L. (1994), Masculino e feminino: a construção social da diferença, Porto, Afrontamento.

Barreto, M. e N. Ellemers (2005), "The burden of benevolent sexism: How it contributes to the maintenance of gender inequalities", en European Fournal of Social Psychology, vol. 35, núm. 5, pp. 633-642.

Bernardes, D. (2003), "Dizer «não» aos estereótipos sociais: as ironias do controlo mental”, en Análise Psicológica, vol. 21, núm. 3, pp. 307-321, <http://www.scielo.oces. mctes.pt/pdf/aps/v21n3/v21n3a05.pdf> [Consulta: Maio de 2015].

Bourdieu, P. eJ. C. Passeron (1978), A Reprodução: Elementos para uma Teoria do Sistema de Ensino, Lisboa, Vega.

Bourdieu, P. (1999), A dominação Masculina, Oeiras, Celta Editora.

Carmino, G. (2005), Pour en finir avec le sexisme, París, L'Échappée.

Carvalho, T., Ö. Özkanli e M. L. Machado (2012), "Perceptions and attitudes of Senior Managers toward gender in academia: a comparative study from Portugal and Turkey", en Educação, Sociedade e Culturas, núm. 35, pp. 45-66.

Chagas Lopes, M. e H. Perista (2010), "Trinta anos de educação, formação e trabalho: convergências e divergências nas trajectórias de mulheres e de homens", en Virgínia Ferreira (org.), A igualdade de mulheres e homens no trabalho e no emprego em portugal. Políticas e circunstâncias, Lisboa, CITE, pp.191-216.

Connell, R. W. (2003), The role of men and boys in achieving gender equality, United Nations, Division for the Advancement of Women.

Descarries, F. e M. Mathieu (2010), Entre le rose et le bleu: stéréotypes sexuels et construction sociale du féminin et du masculin, Québec, Conseil du Statut de la Femme.

De Garay, A. e G. del Valle-Díaz-Muñoz (2011), "Una mirada a la presencia de las mujeres en la educación superior en México", en Revista Iberoamericana de Educación Superior, México, UNAM, vol. III, núm. 6, pp. 3-30, <http://ries.universia.net/index.php/ries/ article/view/96> [Consulta: Julho de 2015].

Eagly, A. e A. Mladinic (1994), "Are people prejudiced against women? Some answers rom research on attitudes, gender stereotypes, and judgments of competence", en European Review of Social Psychology, vol. 5, núm. 1, pp. 1-35.

Féat, D. e A. Salomon (1991), "L'enseignant face aux rôles sexuels des filles et des garçons: une problématique complexe", en Revue des Sciences de l'Éducation, vol. 17, núm. 2, pp. 223-243.

Ferreira, M. (2004), "Sexismo hostil e benevolente: interrelações e diferenças de género", en Temas em Psicologia da SBPa, vol. 12, núm. 21, pp. 119-126.

Fiske, S. e L. Stevens (1993), "What's so special about sex? Gender stereotyping and discrimination", en S. Oskamp y M. Costanzo (eds.), Gender issues in contemporary society: Applied social psychology, Newbury Park, CA, Sage, pp. 173-196.

Formiga, N., S. Gouveia, V. Valdineye y M. Santos (2002), "Inventário de sexismo ambivalente: sua adaptação e relação com o género", en Revista Psicologia em Estudo, vol. 7, núm. 1, pp.103-111.

García, R. et al. (2011), "El patriarcado no es transparente: competencias del profesorado para reconocer la desigualdad", en Revista de Teoría, Investigación y Práctica, vol. 23, núm. 2, pp. 385-397.

Giddens, A. (2010), Sociologia, Lisboa, Fundação Calouste Gulbenkian.

Glick, P. e S. Fiske (1996), "The ambivalent sexism inventory: differentiating hostile and benevolent sexism", en Fournal of Personality and Social Psychology, vol. 70, núm. 3, pp. 491-512.

Glick, P. e S. Fiske (1999), "The ambivalence toward men 
inventory: differentiating hostile and benevolent beliefs about men", en Psychology of Women Quarterly, vol. 23, núm. 3, pp. 519-536.

Glick, P. e S. Fiske (2001), “Ambivalent sexism”, en Mark P. Zanna (ed.), Advances experimental social psychology, San Diego (CA), Academic Press, pp. 115-188.

Glick, P., M. Lameira. e Y. Castro (2002), "Education and catholic religiosity as predictors of hostile and benevolent sexism toward women and men", en Sex Roles, vol. 47, núm. 9/10, pp. 433-441.

Golombock, S. e R. Fivush (1994), Gender development, Cambridge, Cambridge University Press.

INE, (2012), Estatísticas no feminino. Ser mulher em Portugal 2001-2011, Lisboa, Instituto Nacional de Estatística.

Leder, G. (1987), "Teacher student interaction: a case study", en Educational Studies, vol. 18, núm. 3, pp. 255-271.

Leder, G. (1995), "Equity inside the mathematics classroom: fact or artefact?", en W. Secada, E. Fennema y L. Adajian (eds.), New directions for equity in mathematics education, New York, Cambridge University Press, pp. 209-224.

Leder, G. (1996), "Equity in the mathematics classroom: beyond the rhetoric", en L. Parker, L. Rennie y B. Fraser (eds.), Gender, science and mathematics: shortening the shadow, London, Kluver Academic Publisher, pp. 95-104.

Magalhães et al., (2007), "Adaptação do "Inventário de Sexismo Ambivalente" para uma população de estudantes universitários portugueses", en Psicologia: Teoria, Investigação e Prática, vol. 12, núm. 1, pp. 41- 54.

Magno, G. e I. Silova (2007), "Teaching in transition: examining school-based inequities in central/ south-eastern Europe and the former Soviet Union International", en Fournal of Educational Development, vol. 27, núm. 6, pp. 647- 660.

Network, E. (2010), Gender differences in educational outcomes: Study on the measures taken and the current situation in Europe, European Comission, http://eacea. ec. europa. eu/education/eurydice/documents/thematic_ reports/120EN. pdf. [Consulta: Julho de 2015].

Oliveira, J. M., S. Batel e L. Amâncio (2010), "Uma igualdade contraditória? Género, trabalho e educação das elites «discriminadas»", en Virgínia Ferreira (org.), $A$ igualdade de mulheres e homens no trabalho e no emprego em Portugal. Políticas e circunstâncias, Lisboa, CITE, pp.247-260.

Opre, A. e D. Opre (2010), “The gender sterotype threat and the academic performance of women's university teaching staff", en Fournal for the Study of Religions and Ideologies, vol. 5, núm. 14, pp.41-50.

Prentice, D. y E. Carranza (2002), "What women and men should be, shouldn't be, are allowed to be, and don't have to be: The contents of prescriptive gender stereotypes", en Psychology of Women Quarterly, vol. 26, núm. 4, pp. 269-281.

Schneeweis, N. e M. Zweimüller (2012), "Girls, girls, girls: gender composition and female school choice", en Economics of Education Reviere, vol. 31, núm. 4, pp. 482-500.

Vieira, C. (2008), "Estereótipos de Género", en $A$. Vieira, C. (2006), Educação familiar: estratégias para a promoção da igualdade de géneros, Lisboa, Comissão para a Igualdade e para os Direitos das Mulheres.

Rubbim y N. Ramos (orgs.), Estudos da cultura no Brasil e em Portugal, Salvador, EDUFBA, pp. 217-250.

Villas-Boas, S., C. Sales Oliveira e S. Las Heras, (2014). "Tarefas domésticas e género: representações de estudantes do ensino superior", en Revista Ex Aequo, núm. 30, pp. 113-124.

Wall, K.; S. Aboim e V. Cunha (eds.) (2010), A vida familiar no masculino. Negociando velhas e novas masculinidade, Lisboa, Comissão para a Igualdade no Trabalho e no Emprego (Colecção Estudos).

\section{Cómo citar este artículo:}

Sales-Oliveira, Catarina, Susana Villas-Boas y Soledad Las-Heras (2016), “Estereótipos de género e sexismo em docentes do ensino superior", en Revista Iberoamericana de Educación Superior (RIES), México, UNAMIISUE/Universia, vol. VII, núm. 19, pp. 22-41, https://ries.universia.net/article/view/1143/estereotipos-generosexismo-em-docentes-do-ensino-superior [consulta: fecha de última consulta]. 